\title{
Comparison Study of Three Common Technologies for Freezing-Thawing Measurement
}

\author{
Xinbao Yu, ${ }^{1}$ Bin Zhang, ${ }^{2}$ Nina Liu, ${ }^{3}$ and Xiong (Bill) Yu$^{4}$ \\ ${ }^{1}$ Department of Civil Engineering, Case Western Reserve University, 10900 Euclid Avenue, Bingham 203C, Cleveland, \\ OH 44106-7201, USA \\ ${ }^{2}$ Department of Civil Engineering, Case Western Reserve University, 10900 Euclid Avenue, Bingham 212A, Cleveland, \\ OH 44106-7201, USA \\ ${ }^{3}$ Department of Geological Engineering, Chang'an University, Xi'an 710054, China \\ ${ }^{4}$ Department of Civil Engineering, Case Western Reserve University, 10900 Euclid Avenue, Bingham 210, Cleveland, \\ OH 44106-7201, USA
}

Correspondence should be addressed to Xiong (Bill) Yu, xxy21@case.edu

Received 9 December 2009; Revised 11 March 2010; Accepted 2 April 2010

Academic Editor: Jean-François Lataste

Copyright () 2010 Xinbao Yu et al. This is an open access article distributed under the Creative Commons Attribution License, which permits unrestricted use, distribution, and reproduction in any medium, provided the original work is properly cited.

This paper describes a comparison study on three different technologies (i.e., thermocouple, electrical resistivity probe and Time Domain Reflectometry (TDR)) that are commonly used for frost measurement. Specially, the paper developed an analyses procedure to estimate the freezing-thawing status based on the dielectric properties of freezing soil. Experiments were conducted where the data of temperature, electrical resistivity, and dielectric constant were simultaneously monitored during the freezing/thawing process. The comparison uncovered the advantages and limitations of these technologies for frost measurement. The experimental results indicated that TDR measured soil dielectric constant clearly indicates the different stages of the freezing/thawing process. Analyses method was developed to determine not only the onset of freezing or thawing, but also the extent of their development. This is a major advantage of TDR over other technologies.

\section{Introduction}

In cold regions, freeze-thaw cycles induce ground settlement and cause the loss of load bearing capacity of subgrades. Soils can be very strong when they are frozen during the winter but become substantially weak in the spring when they are thawing [1]. This leads to large deflection and accelerates crack initialization in pavement structure. In addition to the detrimental effects on soil mechanical properties, freeze-thaw cycles can also affect the subsurface drainage capability and produce additional soil pressure on the underground structures $[2,3]$. While extensive research have been conducted on completely frozen soils, the current knowledge on soil behaviors during the freezing-thawing process is limited. For example, Spaans and Baker [4] evaluated the use of TDR in the context of freezing and thawing of soils based on a gas dilatomer calibration. FenChong et al. [5] and Fabbri et al. [6] suggested an empirical method to estimate the degree of freezing in porous media based on permittivity. A few factors could have contributed to the lack of development in this area. This includes, for example, the requirements of sophisticate experimental control to ensure uniform freezing/thawing development; the technical challenge of accurately determining the extent of freezing/thawing in soils. Technologies commonly used for field frost measurement do not provide quantitative data on the extent of soil freezing-thawing. This paper describes a comparison study on frost measurement principles, including those based on the electrical resisitivity, the temperature and the dielectric properties. An analyses procedure was developed to determine the extent of soil freezing/thawing from TDR signals.

\section{Background}

2.1. Common Technologies for Frost Measurement. A few technologies are available for frost measurement. All have 
certain advantages. However, their reliability and accuracy to measure freezing-thawing under field conditions are limited. The principles of common types of frost measurement devices are summarized in the following context.

Frost tubes (plastic fluorescein dye tubes) utilize the properties of a fluorescein dye that undergoes a color change as a result of freezing [7]. The change in color can be visually observed. The frost tubes are pretty rugged once installed in the field. Frost tubes readings, however, are taken manually, which is subjective and often results in slow dissemination of critical information.

Resistivity Probes detect the transition of soil between unfrozen and frozen status from the change in its electrical resistivity [8]. Since the change of the electrical resistivity is decided by a number of factors besides the freezing/thawing conditions (i.e., the water content, the soil type, and the ground temperature), determining the freezing-thawing status from the electrical resistivity data is subjected to the operator's judgment. The electrical resistivity probe is generally recommended to be used with supplementary soil temperature data measured by a thermocouple. One type of commonly used electrical resistivity sensor is the moisture blocks constructed from gypsum. There is a concern that the gypsum will deteriorate with time; thus making them unattractive for long-term use $[8,9]$.

Thermocouple has also been used for frost measurement $[10,11]$. Thermocouple provides an accurate and inexpensive way to measure the soil temperature. The soil temperature is then compared with the freezing point of water to determine the freezing/thawing conditions. This technology is easy to install and requires low-cost instrument.

Other technologies that have been employed for frost measurement include Time Domain Reflectometry (TDR) and Nuclear Magnetic Resonant (NMR). Roberson and Siekmeier [9] evaluated the use of a commercial TDR probe for frost measurement. The technology was found perform well for rapid freezing and thawing conditions. The data interpretation, however, was subjective. There remain rooms for improving TDR system design and data analyses. The NMR technology has been found to be very accurate and reliable for determining the amount of water in either solid or liquid status [12]. Its high cost, however, makes it ill-suited for field applications at this moment.

Based on discussions with engineers in professional service, there are high expectations on further improving the existing freeze-thaw instrumentation. This motivates the authors to pursue this study. The goal is to review and compare the principles of common technologies for frost measurement.

\subsection{Principles of Time Domain Reflectometry Technology} (TDR) for Water Content and Freezing/Thawing Conditions. TDR is a guide radar technology. It utilizes the propagation of electromagnetic wave to measure materials properties. The configuration of a typical TDR system as specified in ASTM D6780 [13] is shown in Figure 1(a), which includes a TDR device (pulse generator and sampler), a connection cable, and a measurement probe. The measurement probe generally consists of multiple conductors installed in testing sample. A TDR pulse signal is generated by a signal generator and propagates along the connection cable to the measurement probe. Two major signal reflections occur around the probe, that is, one occurs when the signal enters the probe and one occurs when the signal arrives at the end of probe (Figure 1(b)). The time elapsed between these reflections allows for the determination of the speed of electromagnetic wave in the testing material. Figure 2 shows the standard TDR apparatus that are used in this study [13]. The mold is 4 inch long with 4 inch diameter.

Information commonly obtained on material electrical properties include the apparent dielectric constant $K_{a}$, which is related to the speed of electromagnetic wave in the testing material; and the electrical conductivity $\mathrm{EC}_{b}$, which is related to the rate of electrical energy attenuation. Both quantities can be easily obtained from a TDR signal using accepted algorithms [14, 15].

The principle of TDR technology has been widely applied in different areas. Milestone for its applications in soils is set by the pioneering work of Topp et al. [14]. In fact, TDR is currently the most widely used technology for field monitoring the subsurface water content [16]. Fundamentals of this technology are briefly summarized below.

The travel velocity, $v$, of an electromagnetic wave through a media is decided by its dielectric properties as shown in

$$
v=\frac{c}{\sqrt{K_{a}}}
$$

where $c$ is the velocity of an electromagnetic wave in free space $\left(2.988 \times 10^{8} \mathrm{~m} / \mathrm{s}\right)$ and $K_{a}$ is the dielectric constant (for TDR measurement in soils, this quantity is generally called apparent dielectric constant). The time for the electromagnetic wave traveling down and back along a metallic waveguide of length, $L_{P}$, is given by

$$
t=\frac{2 L_{p}}{v} .
$$

Substituting (1) to (2) yields

$$
K_{a}=\left(\frac{c t}{2 L_{p}}\right)^{2} .
$$

By defining $c t / 2$ as apparent length $l_{a}$, the apparent dielectric constant can be calculated as

$$
K_{a}=\left(\frac{L_{a}}{L_{P}}\right)^{2} .
$$

In displaying a TDR signal, the scale $(c t / 2)$ is typically used in place of travel time $t$. This makes it easy to determine the apparent length $L_{a}$ as illustrated in Figure 3.

Soils are generally multiphased systems consisting of water (both in free and constraint status), soil solids, and air. Water has a dielectric constant of around 81 at $20^{\circ} \mathrm{C}$, which is much larger than that of soil solids (typically around 3 to 7 ) or air (around 1). The large contrast in the dielectric constant of water versus the other phases makes TDR signals very sensitive to the soil water content (Figure 3(b)). 
Figure 3(b) shows the variation of measured TDR signals with gravimetric water content for soils samples of similar dry densities. It is possible to relate TDR measured apparent dielectric constant to soil water content. The relationships are called calibration equations.

Topp et al. [14] showed that for soils with a wide range of mineral content, a single equation was adequate and was independent of soil bulk density, ambient temperature, and salt content. Equation (5) is now widely used as a calibration curve and is referred to as Topp's equation

$$
\begin{aligned}
\theta= & 4.3 \times 10^{-6} K_{a}^{3}-5.5 \times 10^{-4} K_{a}^{2} \\
& +2.92 \times 10^{-2} K_{a}-5.3 \times 10^{-2}
\end{aligned}
$$

where $\theta$ is the volumetric water content (i.e., volume of water compared to total volume of soil). This calibration equation has been confirmed by numerous authors on various soils and currently is the most widely used calibration equation for TDR applications [16].

Siddiqui and Drnevich [17] developed an equation (6) that related TDR measured dielectric constant to gravimetric water content, $w$ (i.e., mass of water compared to mass of dry soil solids). This equation accounts for the effects of soil type and density by incorporating two calibration constants. Besides, it uses the concept of gravimetric water content which is commonly used by geotechnical community [17-19]

$$
w=\frac{1}{b}\left[\frac{\rho_{w}}{\rho_{d}} \sqrt{K_{a}}-a\right],
$$

where $\rho_{d}$ is the dry density of soil, $\rho_{w}$ is the density of water, $a$ and $b$ are soil-dependent calibration constants. Experimental study by Yu and Drnevich [15] found that $a$ is close to 1 (ranging from $0.7-1.2$ ), $b$ is found to be close to 8 (ranging from 7 to 10$)$.

When there is a phase change between water and ice, significant change in the dielectric properties of bulk soil specimen occurs. This is due to the fact that the dielectric constant of ice is approximately equal to that of solids, which is much smaller than the dielectric constant of free water. The effects of freezing/thawing on the soil dielectric constant are similar to those of drying/wetting. This makes it possible for TDR to measure the phase transition between soil water and ice.

\subsection{Electrical Conductivity/Electrical Resistivity from TDR.} TDR measures bulk electrical conductivity $\left(\mathrm{EC}_{b}\right)$ [20] besides the apparent dielectric constant [14]. Various algorithms have been proposed to obtain bulk electrical conductivity from measured TDR waveforms. Nadler et al. [21] investigated most of these methods and concluded that the procedure by Dalton et al. [20] is the most suitable for calculating bulk electrical conductivity from TDR measurement, including the case for layered soils, where TDR measures the average bulk electrical conductivity of the soil.

Dalton's approach to obtain bulk electrical conductivity is based on analyzing the TDR signal attenuation and assumes the TDR signal decays exponentially as it travels

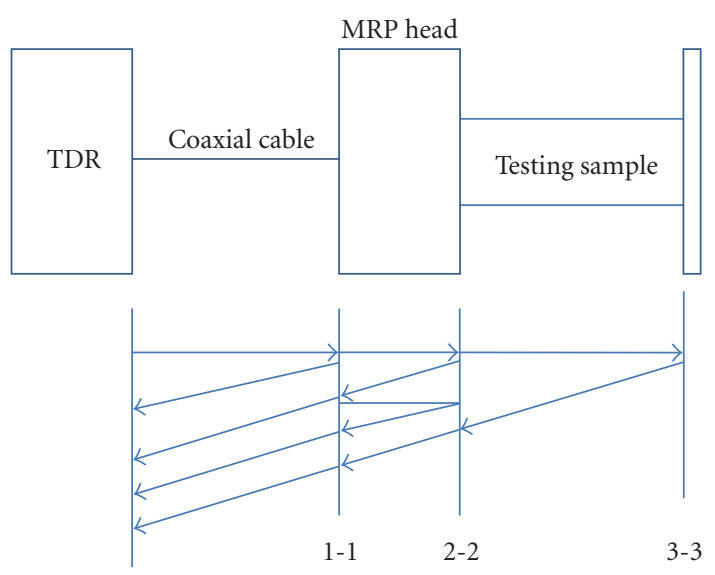

(a)

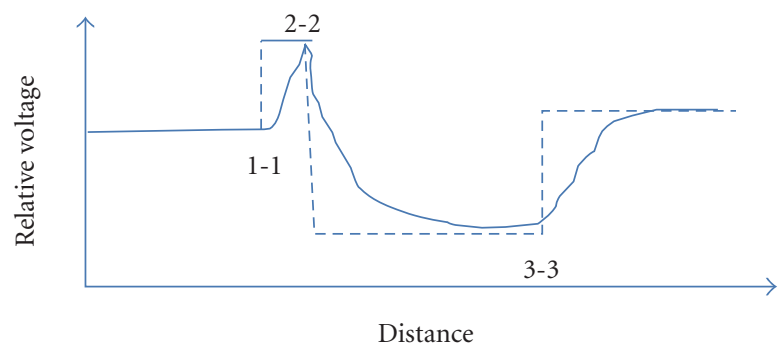

(b)

FIGURE 1: TDR system schematic: (a) reflections in the TDR system; and (b) resulting TDR waveform.

along the measurement probe [22]. This approach has certain problems in that it does not take into account the multiple reflections in TDR waveforms. For signals measured with short probes or in materials with low apparent dielectric constants, the time for multiple reflections is relatively short. These multiple reflections interfere with each other [23] and make it difficult to pick these characteristic voltages from the TDR signal.

To compensate for the shortcomings of Dalton's approach, Yanuka et al. [24] introduced a multiple reflection model and used the amplitude of the signal after all reflections have occurred, $V_{f}$, to obtain the bulk electrical conductivity. Zegelin and White [25] refined the expression Yanuka et al. [24] obtained. The equation for calculating bulk electrical conductivity is

$$
\mathrm{EC}_{b, \mathrm{eff}}=\frac{\sqrt{K_{a}}}{120 \pi L_{P}} \ln \left(\frac{V_{1} V_{f}-V_{s}\left(V_{1}+V_{f}\right)}{V_{s}\left(V_{1}-V_{f}\right)}\right)
$$

where $V_{f}$ is final signal amplitude after all reflections have occurred and the definitions of other voltages are shown in Figure 4.

Although (7) typically gives consistent results, there are also shortcomings, that is,

(1) $\mathrm{EC}_{b}$ is dependent upon $K_{a}$, which means that the error in the determination of $K_{a}$ will be carried over into calculating $\mathrm{EC}_{b}$; 


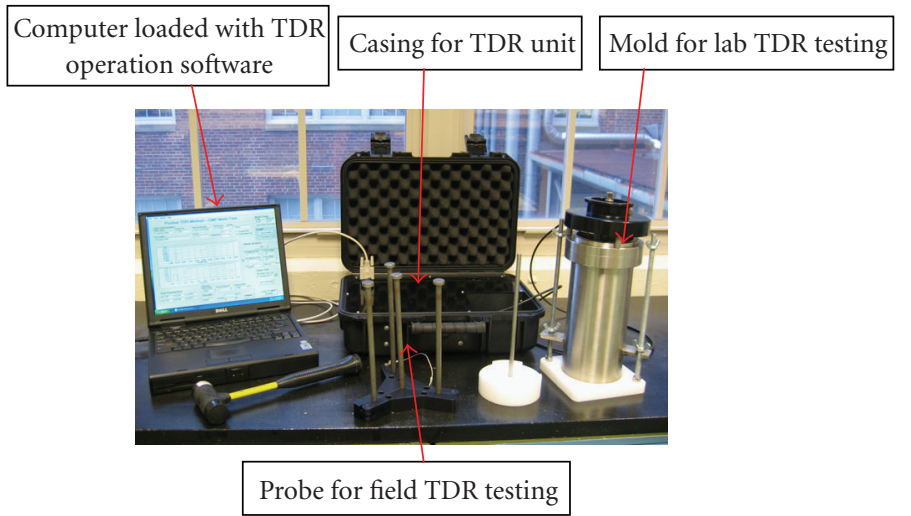

Figure 2: Photo of the TDR system used in this study.

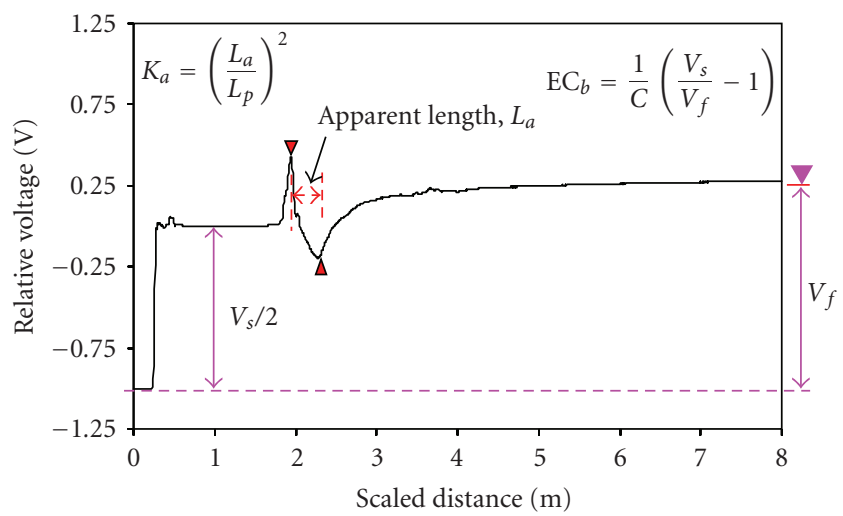

(a)

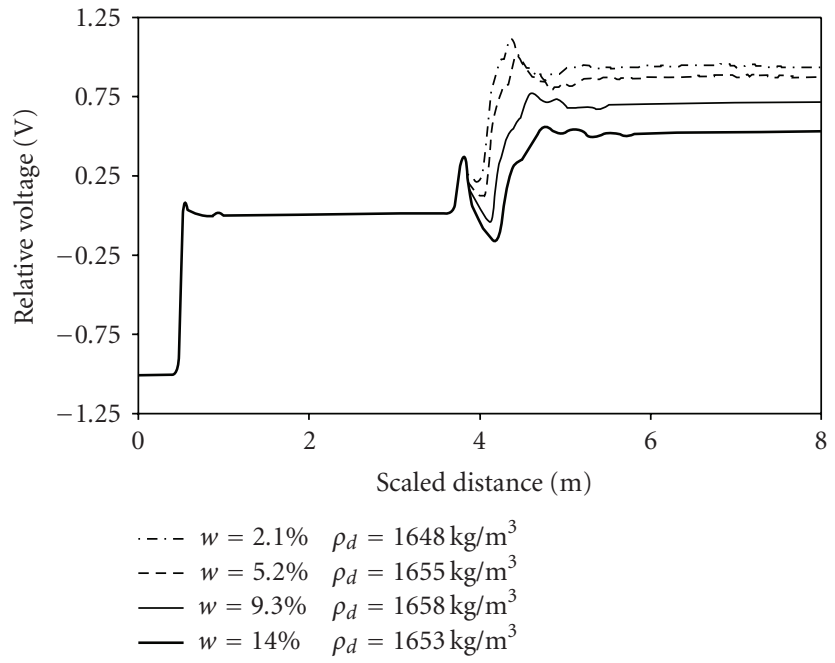

(b)

Figure 3: (a) Example of typical TDR signal; (b) influence of water content on TDR signals at similar dry densities.

(2) It could be difficult, if not impossible, to pick the characteristic voltages levels $V_{s}, V_{1}, V_{f}$, especially for materials with low apparent dielectric constant or short measurement probes.

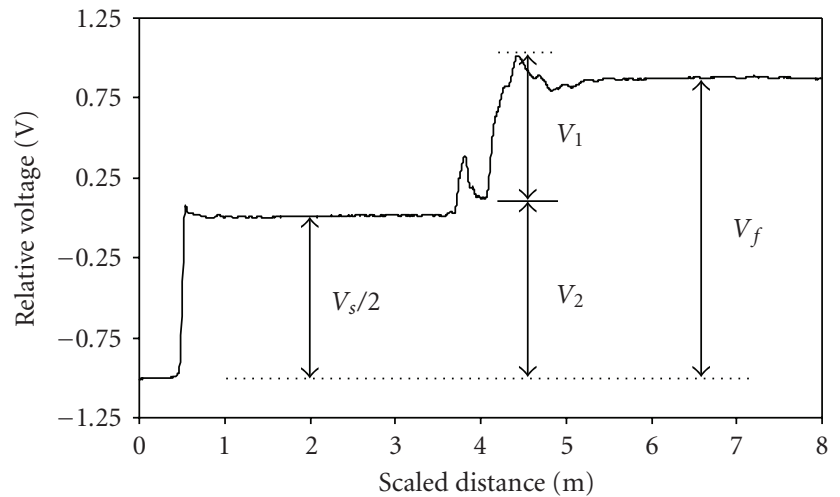

FIgURE 4: Definitions of different voltage levels for a TDR waveform.

Another approach to obtain bulk electrical conductivity is from the long-term response of a TDR system. This idea was initially explored as an effort to directly interpret the TDR waveforms from time domain signals [26]. Topp et al. [27] found that applying this approach for bulk soil electrical conductivity produced satisfactory results.

Analysis using the transmission line theory indicated that the long-term responses of TDR system are equivalent to the analyses by a static circuit model [22]. It is easy to find the final voltage level from the TDR signal. Applying this approach, the electrical conductivity is obtained as

$$
\mathrm{EC}_{b}=\frac{1}{C}\left(\frac{V_{s}}{V_{f}}-1\right)
$$

where $C$ is a constant related to TDR pulse generator and probe geometry. $V_{s}$ and $V_{f}$ are characteristic voltage levels as defined in Figure 4. For coaxial configured probes, that is, the probe include a cylinder metallic mold and a metallic rod installed in the center of the mold

$$
C=\frac{2 \pi L_{P} R_{s}}{\ln (R / r)}
$$

where $L_{p}$ is the embedded length of the measurement probe, $R$ is outer radii of the inner cylinder (the TDR center rod); 


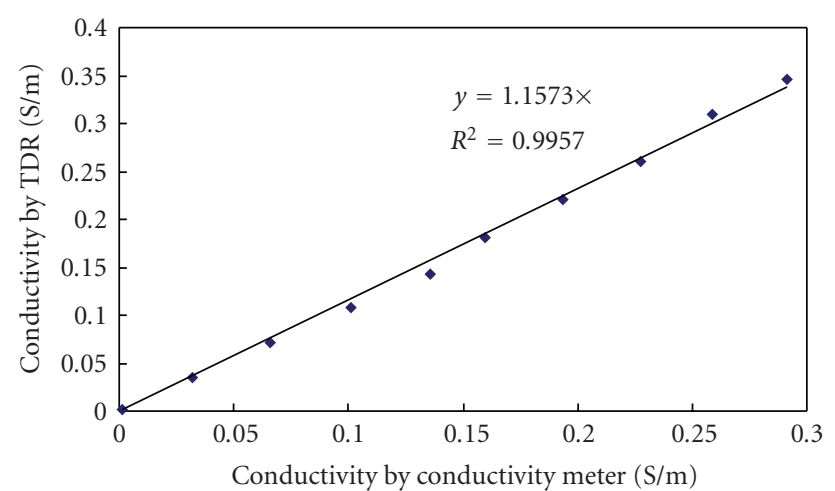

FIGURE 5: TDR measured electrical conductivity versus electrical conductivity meter measurement on bulk water.

$r$ is the inner radii of the outer cylinder (the measurement mold), $R_{s}$ is the internal resistance of the pulse generator (typically $50 \mathrm{ohms}$ ). In practice, $C$ can also be obtained from calibration experiments.

The soundness of (9) was validated by comparing the results of TDR measurement in water with different salinity with those by a bench conductivity meter. The results are shown in Figure 5. There is a good linear relationship between the bulk electrical conductivity by both technologies.

The electrical resistivity, $\rho$, is the inverse of electrical conductivity, which can be easily obtained from the TDR measured electrical conductivity, that is,

$$
\rho=\frac{1}{\mathrm{EC}_{b}} \text {. }
$$

This approach was used for calculating the bulk soil electrical resistivity in this paper.

\section{Experiment Procedure and Apparatus}

An experimental program was conducted to compare the performance of frost measurement based on the temperature, electrical resistivity, and dielectric constant principles. An ASTM standard fine sand was used in the testing program. The soil specimens were first compacted into a compaction mold using standard procedures [13, 28]. A TDR measurement rod was then installed into the center of the mold. This allows for nondestructive monitoring the dielectric constant and electrical resistivity from TDR signals.

The temperature process were measured by a unique type of temperature sensor iButton ${ }^{\circledR}$. The iButton ${ }^{\circledR}$ integrates thermocouple with a processor and storage unit. It can be programmed to automatically sampling and storing the temperature data at preset time intervals. The data can then be retrieved by use of a reading unit (Figure 6). In this study, two iButton ${ }^{@}$ sensors were installed, one close to the top and one close to the bottom of the soil specimen. This allows for determining if the temperature distribution in the specimen is uniform.

A metallic rod was installed in the center of the mold using a guide template. (Guide EM wave TDR requires at least two conductors as waveguide. The metallic rod and metallic mold act as one of the conductors of the waveguide, resp. EM wave propagate along the direction of the rod in the space between the metallic rod and the metallic mold [22].) The sample was then covered with plastic sheet and placed into a freezer (Figure 7). A software developed by the writer was then activated to automatically take TDR signals at 10 minutes interval to monitor the evolution of soil dielectric constant and electrical conductivity until soil specimen was completely frozen.

After the soil specimen was completely frozen under around $-15^{\circ} \mathrm{C}$, it was taken out from the freezer and sat in room temperature of $20^{\circ} \mathrm{C}$ to initialize the thawing process. TDR monitoring program was again activated to monitor signal change during the thawing process.

The dielectric constant, electrical resistivity, and temperature process in soil during the freezing/thawing process by analyzing experimental data. The experiments were repeated on a few specimens and consistent results were obtained. The results representative of experimental observations are shown in the following.

\section{Experimental Results: Comparison of Three Technologies for Freezing-Thawing Measurement}

4.1. Temperature Method. The use of temperature method for freezing-thawing measurement is based on the fact that the temperature of water remains at the freezing point during the crystallization process. Figure 8 plots the measured temperature processes during the freezing/thawing of soil specimen. As described before, two iButtons were installed in the specimen, one on the top and the other in the bottom. Purpose of this arrangement is to assess the spatial variation of thermal field distribution. Comparison of temperature data indicates the variations of temperature within the soil specimen are insignificant. It is also noticed that during the freezing processes, once the temperature dropped to the freezing point (around $0^{\circ} \mathrm{C}$ ), soil temperature remained approximately constant for about 100 minutes (Figure 8(a)). After that temperature started to drop again, which indicated soil water surrounding the iButton ${ }^{\circledR}$ has become completely frozen. From the temperature curve along, it is not possible to tell the amount of water that has been crystallized.

The monitored temperature change during the thawing process resembles the inverse freezing process.

From the experimental observations, it can be seen that given accurately determined melting point, temperature method is able to tell when complete freezing or thawing occurs. It, however, does not tell the extent of freezing/thawing at a given time.

Advantages of temperature method include it is simple and requires inexpensive instrument.

As is known, salt in soil water can reduce its freezing point. This effect can be significant for cold regions where large amount of deicing salt are sprayed during the winter. From physics, the melting point of soil water is also affected 


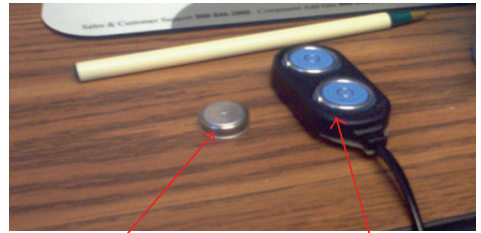

iButton ${ }^{@}$ temperature sensor integrated with thermocouple, microprocessor and storage

FIgure 6: Photo of iButton and reader unit.

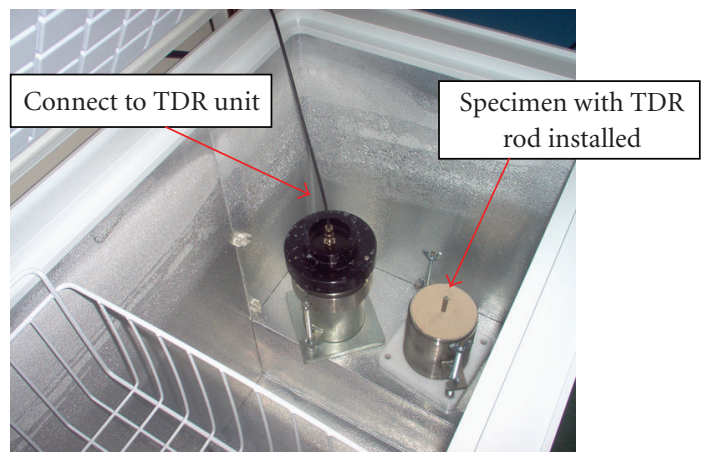

Figure 7: Photo of specimens placed inside freezer

by the external pressure. Thawing caused by traffic loads cannot be detected from soil temperature alone.

4.2. Electrical Resistivity Method. Figure 9 shows the evolution of electrical resistivity (which is obtained from TDR measured electrical conductivity) during the freezing and thawing processes.

For freezing process, the electrical resistivity continues to increase until reach a relatively stable value (which is indicative of soil being completely frozen). It, however, has no indication of the initialization of the soil water freezing process. On the other hand, during the thawing process, the electrical resistivity continues to decrease. There is no indication when the ice is completely thawed.

From the experimental data, it can be concluded that the electrical resistivity might not be a robust indicator for accurately determining the onset or completion of soil water freezing or thawing. This is because the electrical resistivity is not only affected by the freezing-thawing status, but also many other factors such as the soil structure, the hydraulic conductivity, and so forth.

\subsection{TDR Method}

4.3.1. Experimental Phenomena. Examples of TDR monitored signals during freezing are shown in Figure 10, which corresponds to TDR signals at 41 minutes, 91 minutes and 121 minutes after the freezing process started. The return time of TDR signals, and thus the dielectric constant $K_{a}$, decreases with increasing freezing time. This phenomenon is attributed to the increasing amount of soil water becomes

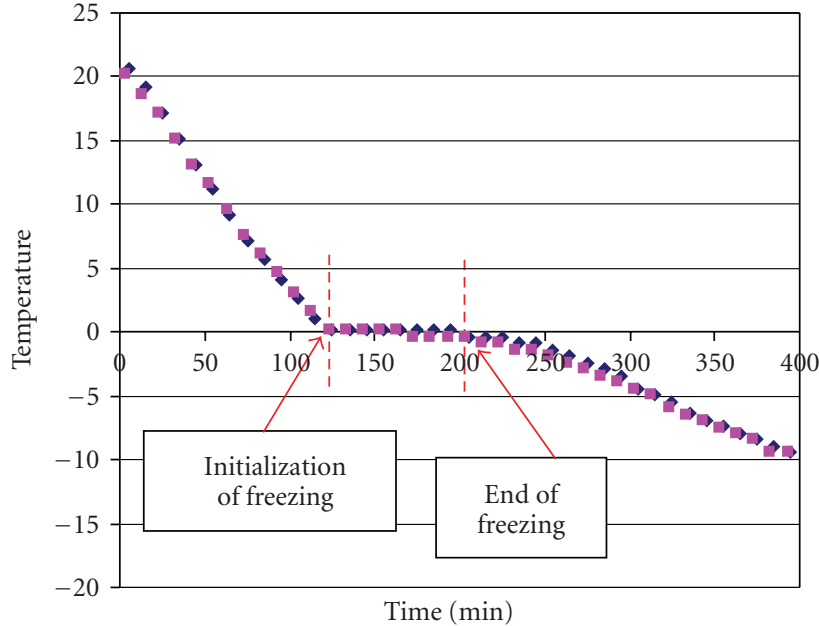

(a)

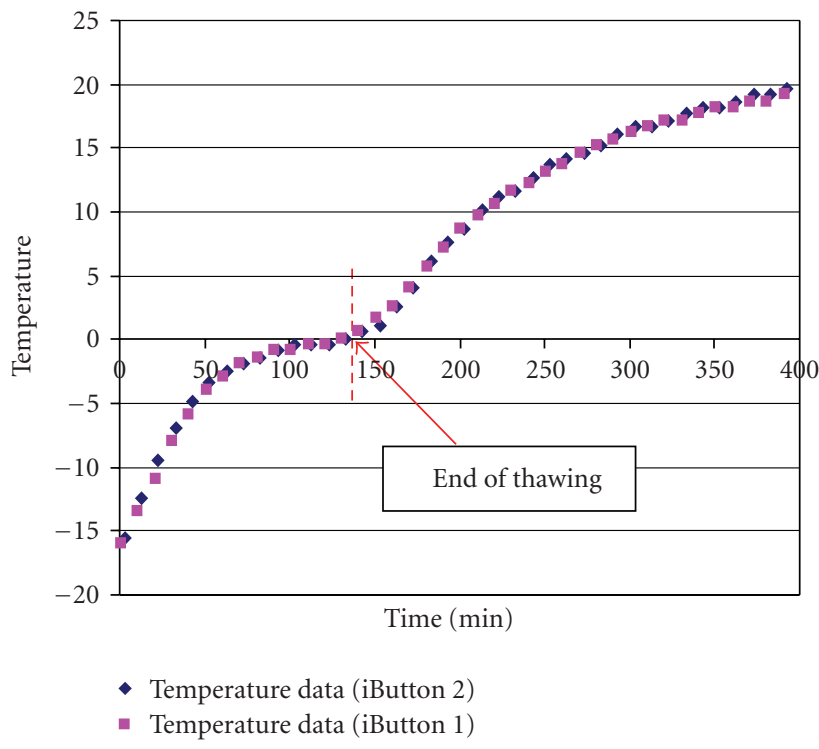

(b)

FIGURE 8: (a) Monitored temperature evolutions during freezing process; (b) temperature during the thawing process (note: iButton 1: located around 1 inch from top surface; iButton 2: located around 1 inch from bottom of soil specimen).

ice. As ice has much smaller dielectric constant (around 4) compared with water (around 81), conversion of water into ice reduces the bulk soil dielectric constant.

Figures 11(a) and 11(b) show the TDR monitored dielectric constant during the freezing-thawing processes, respectively. The progressive change in these signals indicates the TDR sensor is sensitive to freezing-thawing developed inside the soil specimen. As soil water freezes, the bulk soil dielectric constant reduces; while soil water thaws, the bulk soil dielectric constant increases. The signals shown in Figures 11(a) and 11(b) are consistent with this trend. The signals in Figure 11(a) indicate that it takes around 100 minutes for the whole soil specimen to become completely 


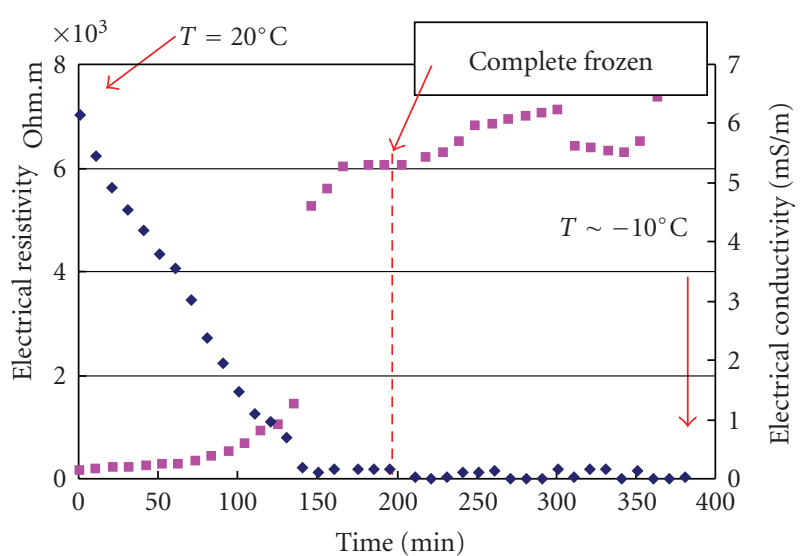

(a)

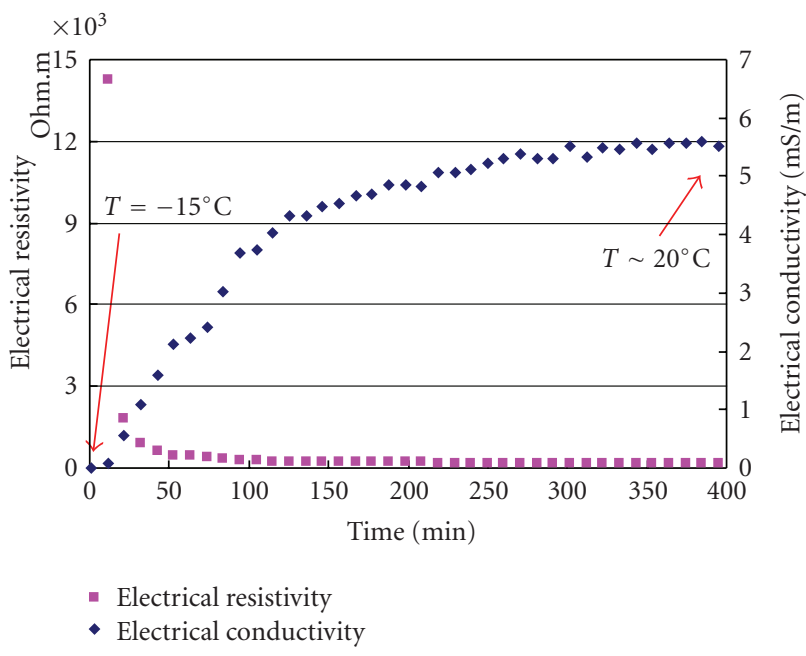

(b)

Figure 9: Monitored electrical resistivity and electrical conductivity: (a) freezing process; (b) thawing process.

frozen. Figure 11(b) shows it takes around 100 minutes for the frozen specimen to completely thaw.

As shown in these figures, different stages of freezing/thawing can be clearly identified from the trend of measured dielectric constant. These different freezing/thawing stages are noted in the figures.

4.3.2. Degree of Freezing/Thawing from TDR Measurement. From the definition, the degree of freezing, $S_{i}$, at a certain point is defined as the percent of soil water that has turned into ice

$$
S_{i}(\%)=\frac{\theta_{\text {thaw }}-\theta_{t}}{\theta_{\text {thaw }}-\theta_{\text {frozen }}} \times 100 \%,
$$

where $\theta_{\text {thaw }}$ is the volumetric liquid water content of soil in complete thaw status, $\theta_{\text {frozen }}$ is the volumetric liquid water content in complete frozen status, $\theta_{t}$ is the volumetric liquid water content of the sample at time $t$.

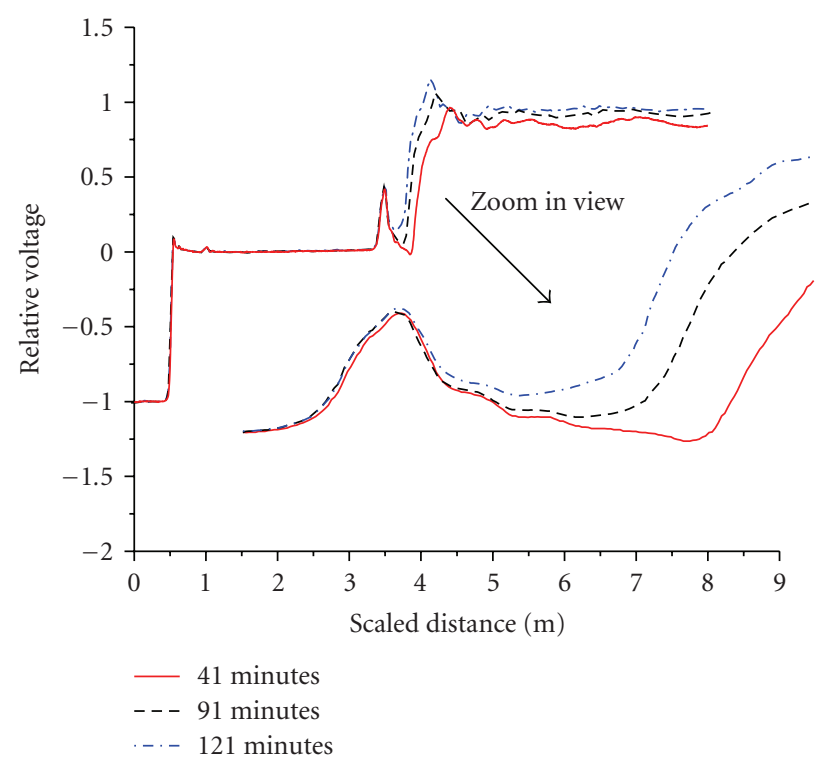

Figure 10: Example TDR signals during the freezing process.

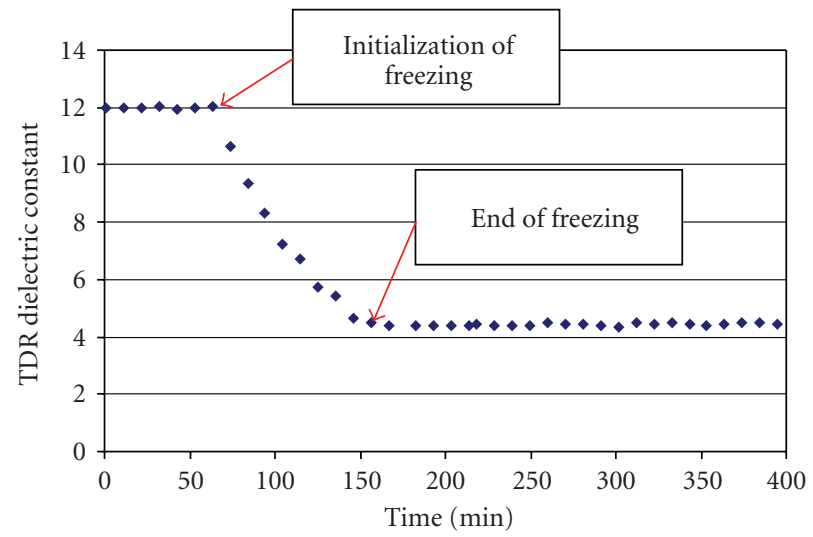

(a)

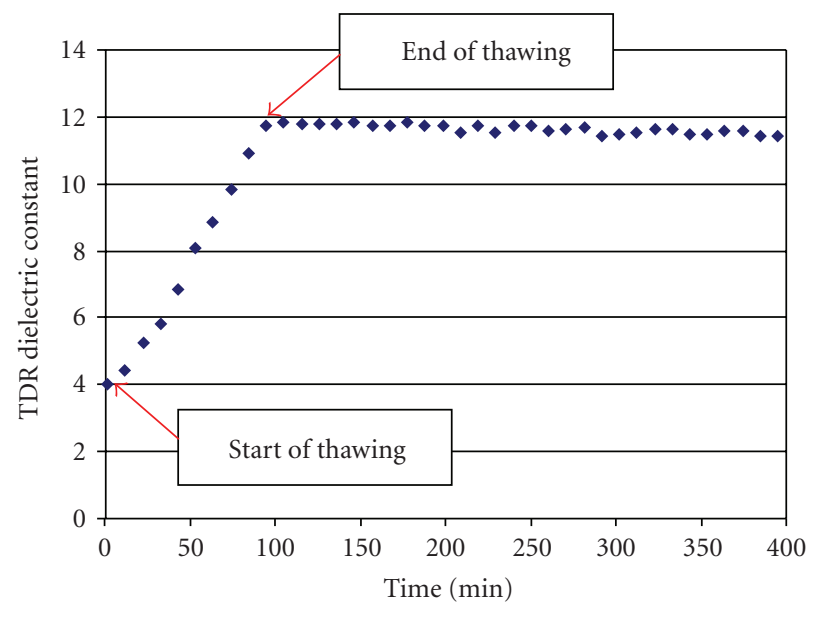

- Dielectric constant

(b)

FIGURE 11: TDR monitored dielectric constant $K_{a}$ : (a) freezing process; (b) thawing process. 
The relationship between the gravimetric water content and the volumetric water content is

$$
\theta=w \frac{\rho_{d}}{\rho_{w}} .
$$

Due to the small magnitude of volume change, the density of soil solids during the freezing-thawing process can be assumed to be constant. Substituting (12) into (11), there is

$$
S_{i}(\%)=\frac{w_{\text {thaw }}-w_{t}}{w_{\text {thaw }}-w_{\text {frozen }}} \times 100 \%
$$

where $w_{\text {thaw }}$ is the gravimetric liquid water content in complete thaw status, $w_{\text {frozen }}$ is the gravimetric liquid water content in completely frozen status, $w_{t}$ is the gravimetric liquid water content of the sample at time $t$.

By use of Siddiqui-Drnevich equation ([17], (6)) to represent the water content terms in (13), the degree of freezing can be expressed by TDR measured soil dielectric constants at different stages of freezing/thawing, that is,

$$
S_{i}(\%)=\frac{\sqrt{K_{a, \text { thaw }}}-\sqrt{K_{a, t}}}{\sqrt{K_{a, \text { thaw }}}-\sqrt{K_{a, \text { frozen }}}} \times 100 \%,
$$

where $K_{a \text {,thaw }}$ is the soil bulk dielectric constant in complete thaw status, $K_{a \text {,frozen }}$ is soil dielectric constant in completely frozen status, $K_{a, t}$ is the soil dielectric constant at time $t$.

Considering the fact that the dielectric constant of soils are temperature-dependent, the dielectric constants in (14) needs to be normalized to a reference temperature. The method of normalization soil dielectric constant to $20^{\circ} \mathrm{C}$ is given by Drnevich et al. 2002 [18, 19]. In the experimental program, the dielectric constant of soil specimens made of over 10 different types of soils each at 5 to 6 different water contents were measured at different temperatures. A few important observations were obtained from the experimental data collected on a variety of soils: (1) the influence of temperature on the bulk dielectric constant are typically small (less than $3 \%$ in the temperature range); (2) the dielectric constant of cohesionless soil decreases with temperature, while (3) the dielectric constant of cohesive soils increases with temperature. Based on analyzing the experimental data, an empirical temperature compensation factor was developed that to normalize the dielectric constant of soil at certain temperature to a standard reference temperature of $20^{\circ} \mathrm{C}$, as shown below

$$
K_{a, 20^{\circ} \mathrm{C}}=K_{a, T^{\circ} \mathrm{C}} \times \mathrm{TCF},
$$

where TCF is Temperature Compensation Factor,

$$
\begin{aligned}
& \text { TCF }=0.97+0.0015 T \text { for cohesionless soils } \\
& \text { TCF }=1.10-0.005 T \text { for cohesive soils. }
\end{aligned}
$$

Due to the range of temperature tested in this previous study, the relationship is applicable to soils in the temperature range of above freezing and under $40^{\circ} \mathrm{C}$.

This method is extended to normalize the soil dielectric constant to $0^{\circ} \mathrm{C}$. A convenient reference temperature is $0^{\circ} \mathrm{C}$, that is, the freezing point of bulk water before ice starts to form. We first normalized the dielectric constant to $20^{\circ} \mathrm{C}$. And then apply the TCF between $20^{\circ} \mathrm{C}$ and $0^{\circ} \mathrm{C}(0.97$ and 1.10 , resp., from (15))

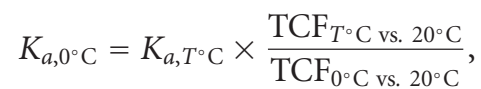

where $\mathrm{TFC}_{T^{\circ} \mathrm{C}}$ vs. $20^{\circ} \mathrm{C}$ is the Temperature Compensation Factor between $T^{\circ} \mathrm{C}$ and $20^{\circ} \mathrm{C}, \mathrm{TFC}_{0^{\circ}} \mathrm{C}$ vs. $20^{\circ} \mathrm{C}$ is the Temperature Compensation Factor between $0^{\circ} \mathrm{C}$ and $20^{\circ} \mathrm{C}$.

With the dielectric constant of soils normalized to that at $0^{\circ} \mathrm{C}$, (14) can be extended to

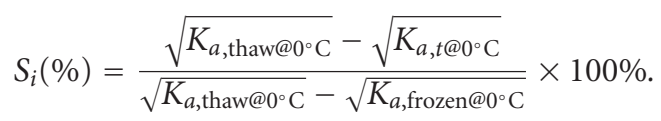

Similarly the concept of degree of thawing, $S_{t}$, can be calculated by

$$
\begin{aligned}
& S_{t}(\%)=\frac{w_{t}-w_{\text {frozen }}}{w_{\text {thaw }}-w_{\text {frozen }}} \times 100 \% \\
& =\frac{\sqrt{K_{a, t @ 0{ }^{\circ} \mathrm{C}}}-\sqrt{K_{a, \text { frozen@ } 0{ }^{\circ} \mathrm{C}}}}{\sqrt{K_{a, \text { thaw } @ 0{ }^{\circ} \mathrm{C}}}-\sqrt{K_{a, \text { frozen@ } 0{ }^{\circ} \mathrm{C}}}} \times 100 \% .
\end{aligned}
$$

With (17) and (18), the degree of freezing of testing specimens at different freezing times were calculated from the measured dielectric constant at time $t$, together with the dielectric constants when specimen is completely frozen and when specimen is completely thaw. Similarly, the degree of thawing of testing specimens at different thawing times were calculated from the measured dielectric constant at time $t$, together with the dielectric constants when specimen is completely frozen and when specimen is completely thaw. The TDR signal analyses included the algorithm widely used by TDR researchers [14-16], it is not elaborated here. The results of degree of freezing at different freezing time and degree of thawing at different thawing time measured with the TDR sensor are shown in Figure 12. This clearly shows the advantages of TDR for frost measurement, that is, it identifies not only the onset and completion of freezing/thawing process, but also the extent of freezing/thawing development.

\section{Conclusion}

A comparison study was conducted to evaluate three commonly used technologies for frost measurement. The principles of these technologies were first reviewed. Freezingthawing experiments were conducted on soil specimens where the electrical resistivity, temperature, and dielectric constant data were simultaneously monitored. The comparison showed that methods based on temperature or electrical resistivity measurement cannot identify the extent of freezing/thawing in soils. They can at best serve as indicator of the complete frozen or completely thaw status. In the meanwhile, TDR technology was found to be able to accurately identify the various stages in the freeze/thaw process (such as the beginning and ending point of freeze/thaw process, the percent of soil water transition between liquid and solid 


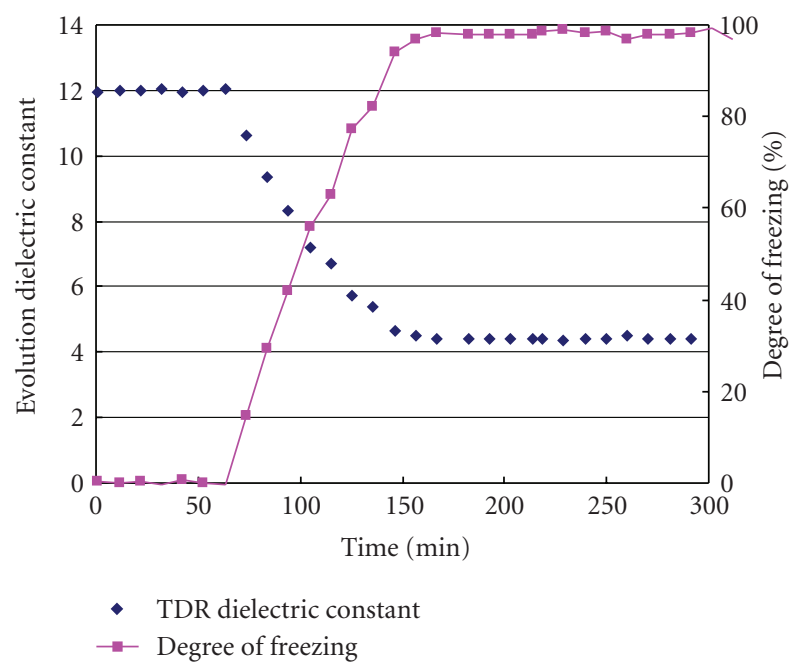

(a)

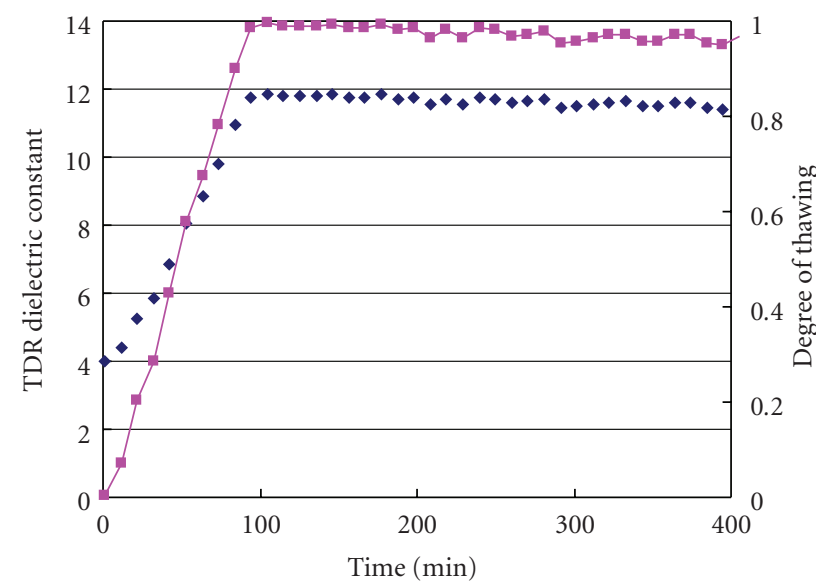

- TDR dielectric constant

$\rightarrow$ Degree of thawing

(b)

FIGURE 12: Degree of freezing/thawing from TDR measured dielectric constant.

status). A simple analyses procedure is developed, where the degree of freezing/thawing can be directly calculated from TDR measured dielectric constant. Fusion of different methods such as TDR and temperature or TDR and electrical resistivity also has potential to further improve the reliability in accurate freezing/thawing measurement.

\section{Acknowledgments}

The authors appreciate the support by staff of Cleveland Water Department (Alex Margevicius, Don Heuer, Teddy Tzeng, and Jonathan Brooks). The authors would also like to thank Roger Green of Ohio Department of Transportation for his comments on the practice issue of frost measurement. This work is partially supported by a REU grant from the National Science Foundation.

\section{References}

[1] D. Levinson, M. Marasteanu, V. Voller, et al., Cost/Benefit Study of: Spring Load Restrictions, Minnesota Department of Transportation, Madison, Wis, USA, 2005, Report No. MN/RC-2005-15.

[2] D. E. Daniel, "Earthen liners for land disposal facilities," in Geotechnical Practice for Waste Disposal '87, R. Woods, Ed., Geotechnical Special Publications no. 13, pp. 21-39, ASCE, New York, NY, USA, 1987.

[3] M. Othman, C. Benson, E. Chamberlain, and T. Zimmie, "Laboratory testing to evaluate changes in hydraulic conductivity of compacted clays caused by freeze-thaw: state-ofthe art," in Hydraulic Conductivity and Waste Contaminant Transport in Soils, D. E Daniel and S. J. Trautwein, Eds., pp. 227-254, American Society for Testing and Materials, Philadelphia, Fla, USA, 1994.

[4] E. J. A. Spaans and J. M. Baker, "The soil freezing characteristic: its measurement and similarity to the soil moisture characteristic," Soil Science Society of America Journal, vol. 60, no. 1, pp. 13-19, 1995.

[5] T. Fen-Chong, A. Fabbri, and A. Azouni, "Transient freezingthawing phenomena in water-filled cohesive porous materials," Cold Regions Science and Technology, vol. 46, no. 1, pp. 12-26, 2006.

[6] A. Fabbri, T. Fen-Chong, and O. Coussy, "Dielectric capacity, liquid water content, and pore structure of thawing-freezing materials," Cold Regions Science and Technology, vol. 44, no. 1, pp. 52-66, 2006.

[7] Minnesota Department of Transportation, Frost Resistivity Probe, User Guide, Minnesota Department of Transportation, Madison, Wis, USA, 1996.

[8] M. D. Burgess and C. L. Hanson, "Automatic soil-frost measuring system," Agricultural Meteorology, vol. 20, no. 4, pp. 313-318, 1979.

[9] R. Roberson and J. Siekmeier, "Using a multi-segment time domain reflectometry probe to determine frost depth in pavement systems," in Effects of Moisture and Temperature on Pavement Systems, pp. 108-113, Transportation Research Board of the National Academies, Washington, DC, USA, 2000, CD-ROM.

[10] E. A. Klute, Methods of Soil Analysis. Part 1. Physical and Mineralogical Methods, Wiley Periodicals, Madison, Wis, USA, 1986.

[11] O. I. Selezneva, Y. J. Jiang, G. Larson, and T. Puzin, "Longterm pavement performance computed parameter: frost penetration," Tech. Rep. no. FHWA-HRT-08-057, Federal Highway Administration, 2008.

[12] K. Yoshikawa and P. P. Overduin, "Comparing unfrozen water content measurements of frozen soil using recently developed commercial sensors," Cold Regions Science and Technology, vol. 42, no. 3, pp. 250-256, 2005.

[13] ASTM D6780, "Standard test method for water content and density of soil in place by time domain reflectometry (TDR)," in Annual Book of Standards, vol. 04.09, pp. 1311-1320, American Society for Testing and Materials, New York, NY, USA, 2003.

[14] G. C. Topp, J. L. Davis, and A. P. Annan, "Electromagnetic determination of soil water content and electrical conductivity measurement using time domain reflectometry," Water Resources Research, vol. 16, pp. 574-582, 1980.

[15] X. Yu and V. P. Drnevich, "Soil water content and dry density by time domain reflectometry," Journal of Geotechnical and 
Geoenvironmental Engineering, vol. 130, no. 9, pp. 922-934, 2004.

[16] K. M. O'Connor and C. H. Dowding, Geomeasurements by Pulsing TDR Cables and Probes, CRC Press, Boca Raton, Fla USA, 1999.

[17] S. I. Siddiqui and V. P. Drnevich, "A new method of measuring density and moisture content of soil using the technique of time domain reflectometry," Tech. Rep. no. FHWA/IN/JTRP95/9, Joint Transportation Research Program, Indiana Department of Transportation, Purdue University, 1995.

[18] V. P. Drnevich, J. Siddiqui, J. Lovell, and Q. Yi, "Water content and density of soil insitu by the purdue TDR method," in Proceedings of the 2nd International Symposium and Workshop on Time Domain Reflectometry for Innovative Geotechnical Applications (TDR '01), Evanston, Ill, USA, Northwestern University, September 2001.

[19] V. P. Drnevich, J. Lovell, J. Tishmack, and X. Yu, "Temperature effects on dielectric constant determined by time domain reflectometry," in Proceedings of the Innovative Applications of TDR Technology (TDR '01), Evanston, Ill, USA, Northwestern University, September 2001.

[20] F. N. Dalton, W. N. Herkelrath, D. S. Rawlins, and J. D. Rhoades, "Time-domain reflectometry: simultaneous measurement of soil water content and electrical conductivity with a single probe," Science, vol. 224, no. 4652, pp. 989-990, 1984.

[21] A. Nadler, S. Dasberg, and I. Lapid, "Time domain reflectometry measurements of water content and electrical conductivity of layered soil columns," Soil Science Society of America Journal, vol. 55, no. 4, pp. 938-943, 1991.

[22] S. Ramo, J. R. Whinnery, and V. D. Theodore, Fields and Waves in Communication Electronics, John Wiley \& Sons, New York, NY, USA, 3rd edition, 1994.

[23] T. J. Heimovaara, "Design of triple-wire time domain reflectometry probes in practice and theory," Soil Science Society of America Journal, vol. 57, no. 6, pp. 1410-1417, 1993.

[24] M. Yanuka, G. C. Topp, S. Zegelin, and W. D. Zebchuk, "Multiple reflection and attenuation of time domain reflectometry pulses: theoretical considerations for applications to soil and water," Water Resources Research, vol. 24, no. 7, pp. 939-944, 1988.

[25] S. J. Zegelin and I. White, "Calibration of TDR for applications in mining, grains, and fruit storage and handling," in Proceedings of the Symposium on Time Domain Reflectometry in Environmental, Infrastructure, and Mining Applications, pp. 115-129, U.S. Bureau of Mines Special Publication, Evanston, Ill, USA, September, 1994, SP 19-94, NTIS PB95-105789.

[26] K. Giese and R. Tiemann, "Determination of the complex permittivity from thin sample time domain reflectometry: implications for twin rod probes with and without dielectric coatings," Water Resource Research, vol. 32, pp. 271-279, 1975.

[27] G. C Topp, S. Zegelin, and I. White, "Impacts of the real and imaginary components of relative permittivity on time domain reflectometry measurements in soils," Soil Science Society of America Journal, vol. 64, pp. 1244-1252, 2000.

[28] ASTM D698, "Standard test methods for laboratory compaction characteristics of soil using standard effort," in Annual Book of Standards, vol. 04.08, pp. 78-88, American Society for Testing and Materials, New York, NY, USA, 2002. 

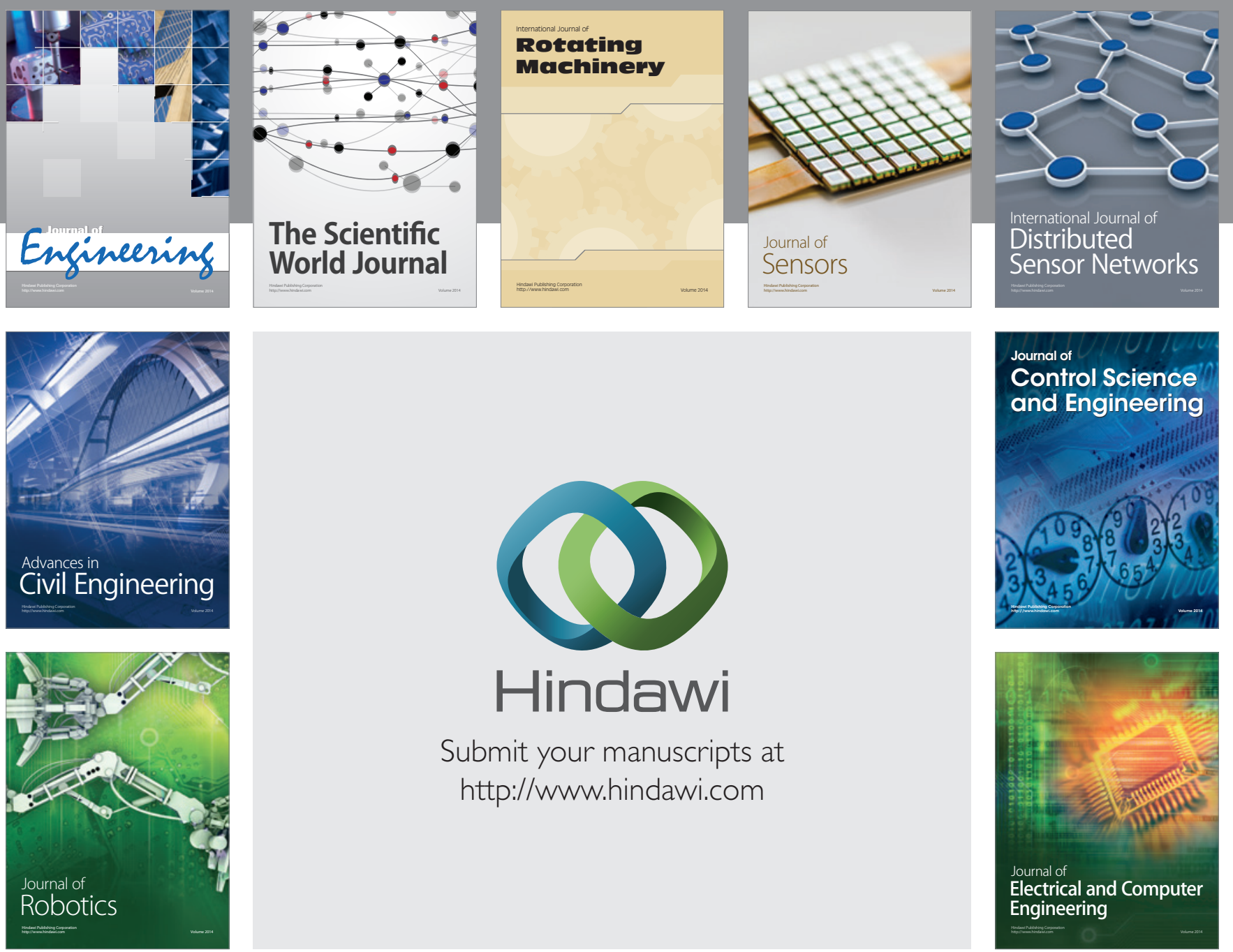

Submit your manuscripts at

http://www.hindawi.com
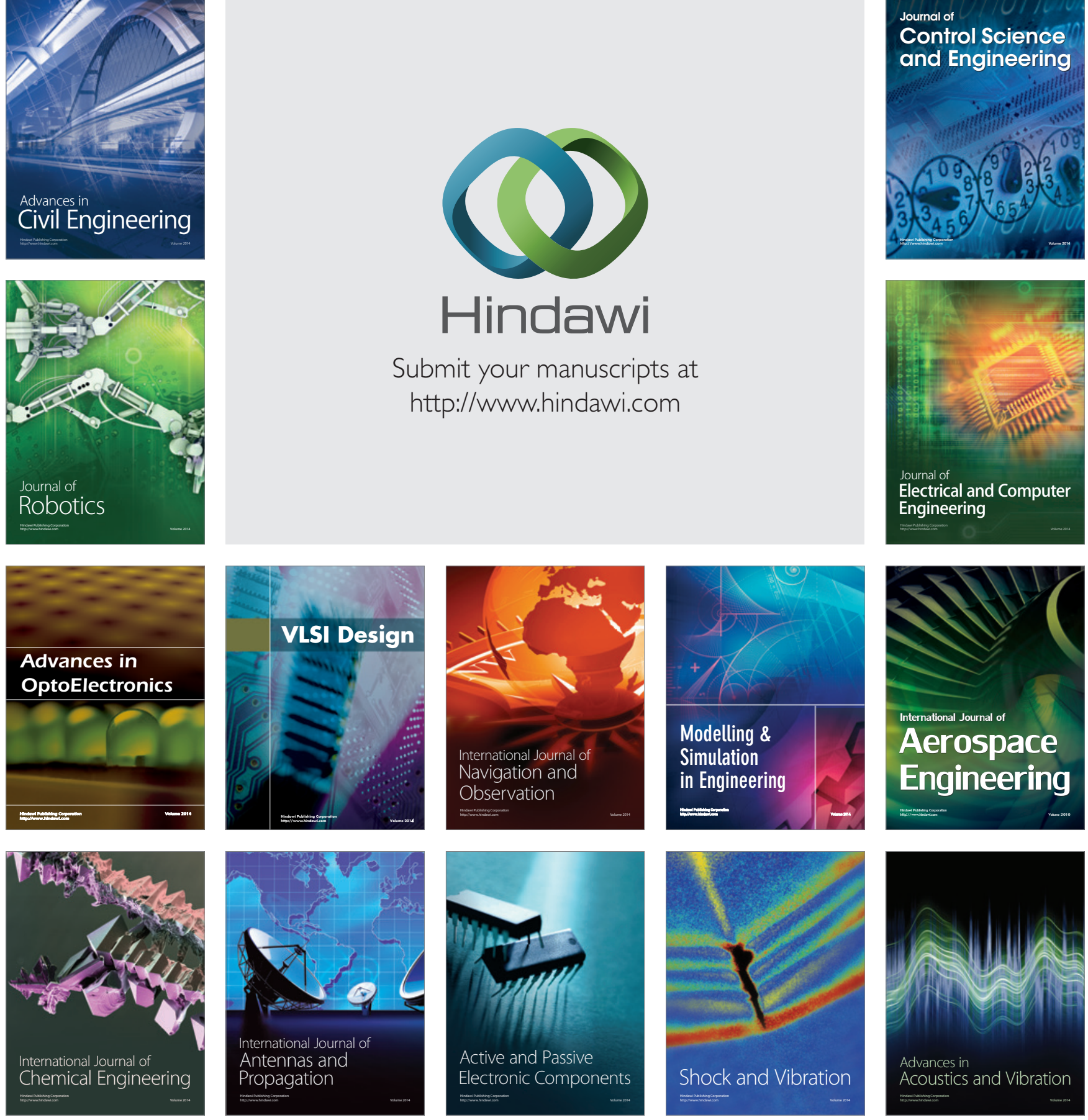